\title{
On the Application of TED Speeches Into Flipped Learning for English Learners-Taking the TED Speeches With the Keyword "Transportation" as an Example*
}

\author{
CHANG Yan \\ Qingdao University of Science and Technology, Qingdao, China
}

\begin{abstract}
Flipped learning is a reversal of the traditional teaching strategy, which has changed the timing of teacher's lectures and homework. In this revolutionary situation, the appropriateness of the before-class videos and other materials and the arrangement of class in the classroom play an important role in the fulfillment of application of the materials. Classical TED speeches are the excellent options for English language learners' flipped learning. This paper tends to make a case study of the application of TED speeches into flipped learning, taking the speeches with the keyword "transportation" as an example.
\end{abstract}

Keywords: application of TED speeches, flipped learning, keyword "transportation"

\section{Introduction}

"Flipped Classroom" was popularized in 2007 by Bergmann and Samms, who adopted a teaching strategy to reverse the timing of in-class lectures and after-class homework. In flipped learning before class video lectures are provided for students and in class exercises (homework) are done under supervision. The flipped learning demonstrates a reversal of traditional teaching where students gain first exposure to new material outside of class, usually via reading or lecture videos, and then class time is used to do the more difficult work of assimilating that knowledge through problem-solving, discussion, or debates. The role of teachers has been greatly changed and the students' motivation and subjectivity has increased. In this new situation, the selection of teaching videos and the arrangement of teachers in class become two vital points, which greatly determine the effectiveness of the new strategy.

\section{TED Speeches-Excellent Materials for English Learners' Flipped Learning}

With great media brand value and benchmarking influence, TED speeches are original, innovative, pioneering, and intellectual. Its advantages can be concluded as the following:

(1) Diversified topics by pioneering experts. TED has broadened its focus from the early emphasis, technology, and design, to include speeches on many scientific, cultural, and academic topics. Past speakers

\footnotetext{
* Acknowledgements: This paper is the achievement of a project sponsored by the Research of Humanities and Social Sciences of Qingdao University of Science and Technology in 2015 (No. 14XD07).

CHANG Yan, lecturer, master, School of Foreign Language Studies, Qingdao University of Science and Technology.
} 
include Bill Clinton, Jane Goodall, Al Gore, Bill Gates, Bono, Google founders Larry Page and Sergey Brin, and many Nobel Prize winners. With abundant topics and with the freshest content by the most respectable giants in the world, TED speeches offer the most advanced material to the audience, which can broaden the audience's horizon, and realm of knowledge.

(2) Vivid, intriguing, and simple forms. Speakers address a wide range of topics within the research and practice of science and culture, often through storytelling in a maximum of 18 minutes. They often present their ideas in the most innovative and engaging ways they can. Hence, they usually make in-depth explanations of profound things in simple ways for common people to understand. TED speeches are wonderful opportunities for English leaners to gain the knowledge besides English language itself.

(3) Free online viewing. Since June 2006, TED talks have been offered for free viewing online, through TED.com. By November 2012, TED talks had been watched over one billion times worldwide. As of March 2016, over 2,400 talks are freely available on the website. Fabulous but free online TED speeches are a blessing for English learners to improve themselves; they can arrange their learning according to their own preferences and requirements very flexibly.

In brief words, the features of TED speeches are just accordant with the features of flipped learning (Individuality of learning space, flexibility of learning environment, interactivity of dynamic discussion, in-depth reflection, and professionalism of the instruction), and they are the excellent materials for English language learners to make options. With classical TED speeches, students' own motivation to watch and to learn can be greatly strengthened.

\section{A Key Point of Flipped Learning: The Change of Teachers' Role —From a Commander to a Facilitator}

Professional teachers are supposed to take constant observation of the students' learning, make timely feedback to their related questions and make comprehensive assessment of the learning process. What is more, qualified teachers also make reflections about the practice, communicate with other peers, and improve their teaching methods and strategies. All in all, the teachers in flipped learning play the role of a helper instead of a commander in traditional teaching in class, they help the students make a flexible environment and a "student-centered" learning culture and help them reconstruct their learning activity, in which students' subjectivity and enthusiasm can get greatly strengthened.

In order to carry out flipped learning, teachers should strive to effectively arrange the time in class, since lectures by teachers take place outside of class and class time is devoted to group and individual problem solving, discussion, critical thinking, and experiments. Full preparation and careful observation are quite necessary to teach students in accordance with their aptitude. The success of flipped learning lies in the "absorption and internalization" of the knowledge in students' learning process.

In flipped learning, the class is transformed into a dynamic, interactive learning environment, while teachers are no more than a commander in the traditional classroom, they are the facilitators and able to work one-to-one with students, clarify assignments, and offer help personally as needed. Teachers pay more attention to the students' effectiveness and ability to learn. 


\section{A Case Study-Taking the Application of TED Speeches With the Keyword "Transportation" as an Example}

A major benefit of flipped teaching is that teachers spend more time working directly with students instead of lecturing to them. This change must necessarily bring out the change of mode of teaching in class. So how the teacher arranges the time in class and carries out the application of flipped learning turns out to be a decisive problem.

There is no set formula for the flipped classroom. Each implementation will differ because of wide variables such as class size, discipline, teaching style, technology, and resources. A common theme is that there is a greater focus on students' concept exploration, meaning making, and demonstration with more opportunities for discussion, formative assessment, and feedback.

In today's multimedia world, flipped learning becomes much more practical with the classical videos, which can take use of the new education notion, new technology, and new teaching methods, combining the teachers with the students, combining teaching theories with teaching practice, so as to construct an integrated and interactive teaching mode.

Taking the TED speeches with the keyword "transportation" as an example, this is a suggested application into flipped learning from the perspective of the teacher.

As the warming-up section, before class the teacher can hold a discussion or raise some simple questions about the latest news concerning "transportation" in QQ group online. In order to take part in the discussion, the students are to consult some reference materials.

Then the teacher can introduce the TED speeches with the keyword "transportation". The following are some related TED speeches:

(1) Sebastian Thrun: Google's Driverless Car;

(2) Anna Mracek Dietrich: A Plane You Can Drive;

(3) Dennis Hong: Making a Car for Blind Drivers;

(4) Paul MacCready: A Flight on Solar Wings;

(5) Graham Hawkes: A Flight Through the Ocean;

(6) Paul Moller: My Dream of a Flying Car;

(7) Bill Ford: A Future Beyond Traffic Gridlock;

(8) Shai Agassi: A New Ecosystem for Electric Cars;

(9) Ueli Gegenschatz: Extreme Wingsuit Flying;

(10) Yves Behar: A Supercharged Motorcycle Design;

(11) Robin Chase: The Idea Behind Zipcar (and What Comes Next);

(12) Bertrand Piccard: My Solar-Powered Adventure;

(13) Andreas Raptopoulos: No Roads? There's a Drone for That;

(14) Chris Gerdes: The Future Race Car-150mph, and No Driver;

(15) Christopher C. Deam: The Airstream, Restyled;

(16) Gary Lauder: Take Turns;

(17) Larry Burns: The Future of Cars; 
(18) Peter van Manen: How Can Formula 1 Racing Help...babies?;

(19) Janette Sadik-Khan: New York's Streets? Not So Mean Any More;

(20) Jonas Eliasson: How to Solve Traffic Jams;

(21) Jennifer Healey: If Cars Could Talk, Accidents Might be Avoidable;

(22) Chris Urmson: How a Driverless Car Sees the Road.

The students are suggested to watch each of the speeches before class by themselves. They may watch the speech firstly without the subtitles to get the basic idea, then with English subtitles for details, and lastly with Chinese subtitles to make sure they grasp all the points.

In class, one student or a group of students are to make a presentation about the speech, which may cover the background of the speaker, some vocabulary and political and geographical terms, the speaker's main idea, and even some questions for the audience to reflect and answer. Each student can share with the classmates about the details which have impressed him or her deeply, or about the details which he or she cannot agree with, and explain the reasons, in this way, their critical thinking abilities can be gradually motivated.

Here are some brainstorming topics for English majors to discuss in class after watching the TED speeches at home:

(1) Collect terms and set expressions about traffic and transportation, share with your classmates.

(2) Can you drive? If yes, please tell others some interesting experience about driving.

(3) Do you know some common senses about cars and driving?

(4) Do you know some car etiquettes?

(5) Say something about the history of automobile development, and the history of the American auto industry.

(6) Discuss about the difference of automobile cultural in America and in China.

(7) How many different means of transportation do you know? Compare them from different aspects, what are the advantages and disadvantages of each one?

(8) How much do you know about the traffic situation in your city?

(9) How much knowledge do you have about the vehicle safety?

(10) How many car brands and car companies do you know?

(11) Do you use Uber, and any other car-taking apps?

(12) Do you know any vehicles specially designed for the disable? How do they work?

(13) Do you know any new-powered cars? What do you think the future of cars will be like?

(14) Do you know any car-parking service? What can they do for the customers?

(15) How much do you know about the traffic signs, which is very important for qualified drivers? Do you know any specially designed signs, what do they mean?

After class, the teacher may design an online feedback questionnaire to figure out the students' personal requirements for improvements in the next class. And the teacher can propose the students watch another video entitled "American Transportation" from American Revealed series to get more knowledge about the traffic situation and technology in America. Hence students can gain a comprehensive idea of transportation in the world, besides the English language learning, and their horizon can get broadened and improved. 


\section{Conclusion}

In flipped learning, traditional teaching mode has been reformed, the role of teachers has been changed from a commander to a facilitator or a helper, and the students become the center of the education. Abundant free classical TED speeches on the Internet have offered a profusion of teaching materials for English learning. In the teaching process, how to make options from the TED speeches and how to arrange the application of flipped learning for students turn out to be a problem worth teachers' careful and meticulous meditation. This paper tends to offer a tentative application of TED speeches with the keyword "transportation" into flipped learning, some methods and strategies have been proposed in hope of improving students' ability and the learning quality.

\section{References}

Hmelo-Silver, C. E. (2013). Creating a learning space in problem-based learning. Interdisciplinary Journal of Problem-Based Learning, 7(1).

HUA, W. F. (2001). 试论外语教师在自主学习模式中的定位 (On the role location of foreign language teachers in autonomous learning mode). 外语研究, 3, 76-79.

Johnson, L., \& Renner, J. (2012). Effect of the flipped classroom model on secondary computer applications course: Student and teacher perceptions, questions and student achievement (Unpublished doctoral dissertation, University of Louisville, Kentucky).

LI, X. (2015). 翻转课堂中大学英语教师的角色转型 (The role transformation of college English teachers in the flipped classroom). 英语广场, 4, 74-75.

Strayer, J. (2012). How learning in an inverted classroom influences cooperation. Learning Environments, 15(2), 171-193.

WANG, X. D., \& ZHANG, C. J. Z. (2013). 翻转课堂在大学教学中的应用研究 (The application research of flipped classroom in university teaching一A case study on professional English of educational technology). 现代教育技术, 8, 11-16.

ZHONG, X. L., SONG, S. Q., \& JIAO, L. Z. (2013). 信息化环境中基于翻转课堂理念的教学设计研究 (Instructional design based on the idea of the flipped classroom in ICT environment). 开放教育研究, 1, 58-64.

ZENG, Z. (2012). 反转教学的特征、实践及问题 (The fipped instruction: Feature, practice and problems). 中国电化教育, 7 , 114-117. 